\title{
Models for Gas Hydrate-Bearing Sediments Inferred from Hydraulic Permeability and Elastic Velocities
}

$$
\begin{aligned}
& k_{e f f}=\frac{n_{c}(1-\phi)}{6}\left(k_{h}+\frac{4 \mu_{h}}{3}\right) S_{n} \\
& \mu_{e f f}=\frac{3 k_{e f f}}{5}+\frac{3 n(1-\phi) \mu_{h} S_{\tau}}{20}
\end{aligned}
$$

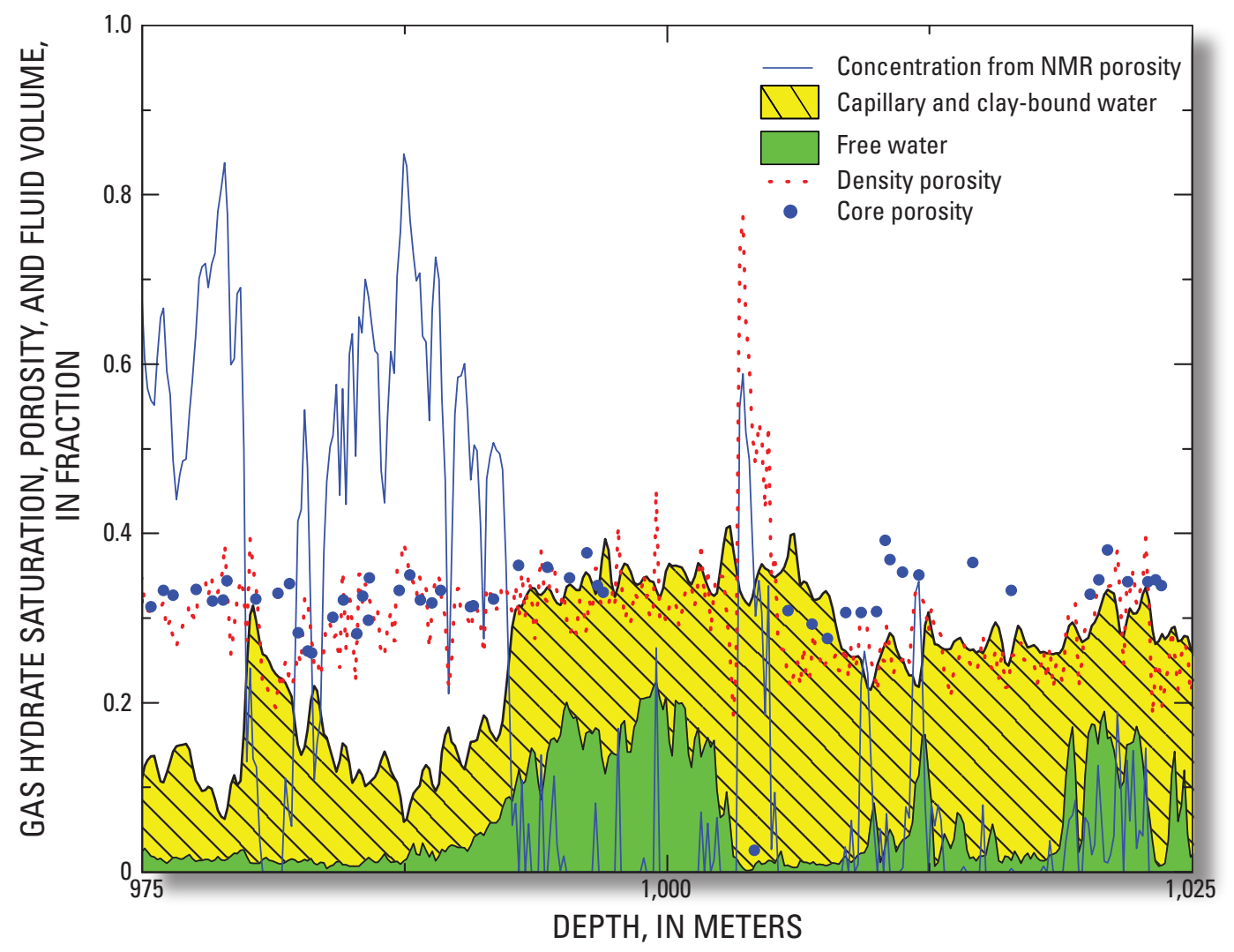

Scientific Investigations Report 2008-5219 


\section{Models for Gas Hydrate-Bearing Sediments Inferred from Hydraulic Permeability and Elastic Velocities}

By Myung W. Lee

Scientific Investigations Report 2008-5219 


\title{
U.S. Department of the Interior DIRK KEMPTHORNE, Secretary
}

\author{
U.S. Geological Survey \\ Mark D. Myers, Director
}

U.S. Geological Survey, Reston, Virginia: 2008

For product and ordering information:

World Wide Web: http://www.usgs.gov/pubprod

Telephone: 1-888-ASK-USGS

For more information on the USGS - the Federal source for science about the Earth, its natural and living resources, natural hazards, and the environment:

World Wide Web: http://www.usgs.gov

Telephone: 1-888-ASK-USGS

Any use of trade, product, or firm names is for descriptive purposes only and does not imply endorsement by the U.S. Government.

Although this report is in the public domain, permission must be secured from the individual copyright owners to reproduce any copyrighted materials contained within this report.

Suggested citation:

Lee, M.W., 2008, Models for gas hydrate-bearing sediments inferred from hydraulic permeability and elastic velocities: U.S. Geological Survey Scientific Investigations Report 2008-5219, 14 p. 


\section{Contents}

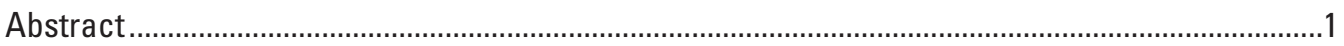

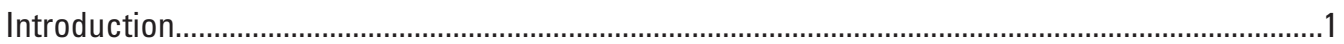

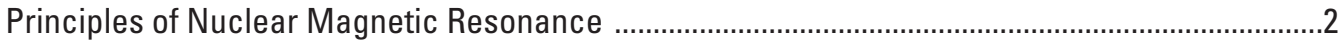

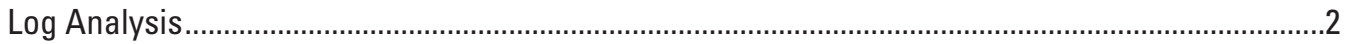

Nuclear Magnetic Resonance, Density, and Core Porosities .................................................3

Nuclear Magnetic Resonance and Water-Filled Porosities.......................................................3

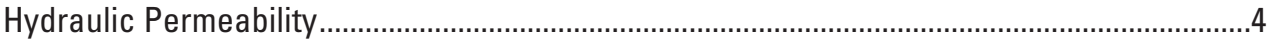

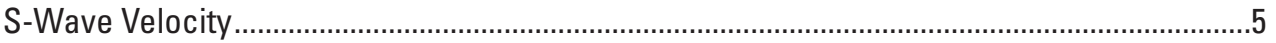

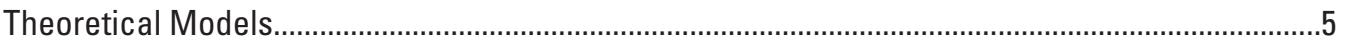

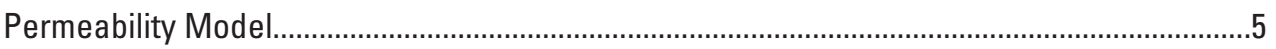

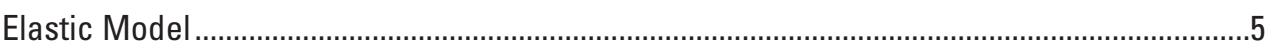

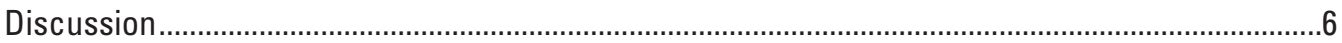

Permeability of Non-Gas Hydrate-Bearing Sediments ............................................................6

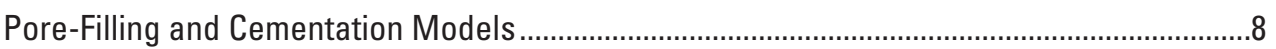

Combination of Permeability and Elastic Velocities...............................................................

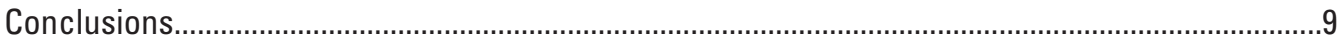

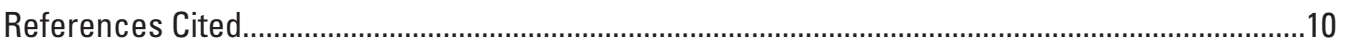

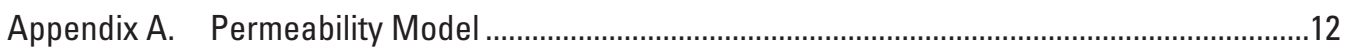

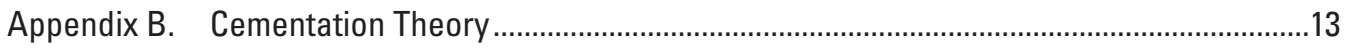

Appendix C. Three-Phase Biot-Type Equation …………...........................................................14

\section{Figures}

1. Comparison of various measured porosities and fluid volumes..........................................

2. Comparison among density, water-filled, and nuclear magnetic resonance (NMR) porosities within the gas hydrate interval $(891-1,109 \mathrm{~m})$.....................4

3. Hydraulic permeability measured from the nuclear magnetic resonance (NMR) log at the Mallik $5 \mathrm{~L}-38$ well is plotted with respect to NMR porosity

4. Relative permeability calculated from various permeability models and measured relative permeability at the Mallik $5 \mathrm{~L}-38$ well ..................................................

5. Results of elastic velocities predicted from the cementation and pore-filling models with measured velocities...................................................................

6. Measured permeabilities with least-squares fitting curves ..............................................

7. Calculated relative permeability and elastic velocities using the grain-coating (cementation) model and pore-filling model with measured permeabilities and velocities

\section{Table}

1. Elastic parameters used for computing elastic velocities 


\title{
Models for Gas Hydrate-Bearing Sediments Inferred from Hydraulic Permeability and Elastic Velocities
}

\author{
By Myung W. Lee
}

\begin{abstract}
Elastic velocities and hydraulic permeability of gas hydrate-bearing sediments strongly depend on how gas hydrate accumulates in pore spaces and various gas hydrate accumulation models are proposed to predict physical property changes due to gas hydrate concentrations. Elastic velocities and permeability predicted from a cementation model differ noticeably from those from a pore-filling model. A nuclear magnetic resonance (NMR) log provides in-situ water-filled porosity and hydraulic permeability of gas hydrate-bearing sediments. To test the two competing models, the NMR log along with conventional logs such as velocity and resistivity logs acquired at the Mallik 5L-38 well, Mackenzie Delta, Canada, were analyzed. When the clay content is less than about 12 percent, the NMR porosity is "accurate" and the gas hydrate concentrations from the NMR log are comparable to those estimated from an electrical resistivity log. The variation of elastic velocities and relative permeability with respect to the gas hydrate concentration indicates that the dominant effect of gas hydrate in the pore space is the pore-filling characteristic.
\end{abstract}

\section{Introduction}

Gas hydrate affects the physical properties of sediments by increasing elastic velocities and electrical resistivity and by decreasing hydraulic permeability. In order to estimate in-situ gas hydrate concentration in sediments, predictive models for the changes of physical properties due to gas hydrate should be known, and these changes depend on the nature of porescale interactions between gas hydrates and porous media.

Two competing theories/models have been proposed for elastic velocities-a cementation model and a porefilling model. The mathematical description of velocities for a pore-filling model in this report is identical to that for a load-bearing model (Kleinberg and others, 2005), whereby the gas hydrate becomes a component of the solid phase and the term "pore-filling" is used to emphasize that gas hydrate does not cement grains nor is it floating (Helgerud and others, 1999) in the pore space. Dvorkin and Nur (1993) proposed a cementation model, wherein gas hydrate cements or coats the grains and significantly affects the elastic velocities of gas hydrate-bearing sediments (GHBS). For example, this model predicts dramatic increases of the compressional wave (P-wave) and shear wave ( $\mathrm{S}$-wave) velocities even with a small amount of gas hydrate because intergranular gas hydrate cementation significantly increases the elastic moduli of the dry-rock frame. Ecker and others (1998) applied the cementation theory to the amplitude-versus-offset (AVO) analysis of a bottom-simulating reflection observed at the Blake Outer Ridge and concluded that the observed AVO does not agree with that predicted by the cementation model. However, Guerin and others (1999) estimated the amount of gas hydrate from the bulk modulus of GHBS at the Ocean Drilling Program (ODP) well 995, Blake Outer Ridge, assuming that gas hydrate uniformly coats the grain and showed that estimates are comparable to those from the electrical resistivity log.

Several different pore-filling models have been suggested. Hyndman and Spencer (1992) used a velocity model that predicts the velocity of GHBS by assuming the porosity reduction caused by infilling with gas hydrates has the same effect on velocity as the normal porosity reduction with depth due to compaction. Lee (2002) proposed a modified BiotGassmann theory by deriving the Biot coefficient appropriate for unconsolidated sediments and by treating the gas hydrate as part of the dry-rock frame, which reduces the porosity of sediments. Helgerud and others (1999) and Jakobsen and others (2000) proposed velocity models based on the effective medium theory. Lee (2007) developed a three-phase Biot-type equation (TPBE) on the basis of percolation theory by Leclaire and others (1994) by treating gas hydrate as a separate phase. A significant difference between these pore-filling models and the cementation model is that the velocity increase with respect to gas hydrate concentration is monotonic for the porefilling model, but rapid for the cementation model. Because of rapid increases in both $\mathrm{P}$ - and $\mathrm{S}$-wave velocities by the cementation theory, this theory predicts that the $V_{\mathrm{p}} / V_{\mathrm{s}}$ ratio of GHBS is less than 2 at small gas hydrate concentrations in unconsolidated sediments, which point to a consolidated nature of GHBS, whereas the pore-filling model predicts an unconsolidated nature of GHBS. 
Measuring the permeability of GHBS is difficult partly because of the ephemeral nature of gas hydrate. Winters and others (1999) measured an anomalously high permeability of GHBS collected at the Mallik 2L-38 well, Canada. This was attributed either to the presence of natural/test-induced fractures, or to the difficulty of performing permeability tests on specimens that contain different phase mixtures without affecting the sample itself. Kleinberg, Flaum, Griffin, and others (2003) measured the permeability of the Berea Sandstone with various gas hydrate concentrations using nuclear magnetic resonance (NMR) data interpretation with the Kenyon relation (Kenyon, 1992).

The NMR tool has the ability to measure water-filled porosity and permeability in sediments (Singer and others, 1997), thus can be used to investigate how gas hydrate accumulates in pore spaces. Akihisa and others (2002) applied the NMR total porosity data to estimate in-situ gas hydrate concentration at the Nankai-trough well, offshore southeast Japan. Kleinberg, Flaum, Griffin, and others (2003) and Kleinberg, Flaum, Straley, and others (2003) used the NMR measurements to quantify pore-size control of hydrate-bearing formations; their study indicated that when substantial hydrate saturations were achieved, hydrate tended to accumulate in the largest pore spaces. In the present study, permeability data acquired from the NMR log and other geophysical logs at the Mallik 5L-38 well, Canada, are analyzed to investigate the relation between natural gas hydrates and a sediment's pore spaces by inferring their bulk properties such as elastic velocities and permeability. For elastic velocities, a pore-filling model using the simplified three-phase Biot-type equation (STPBE) and a cementation theory by Dvorkin and Nur (1993) are used. A brief description of the theoretical permeability model of GHBS proposed by Kleinberg, Flaum, Griffin, and others (2003) is briefly described in appendix A, velocities of the cementation theory by Dvorkin and Nur (1993) are shown in appendix B, and the STPBE is shown in appendix C.

\section{Principles of Nuclear Magnetic Resonance}

An NMR measurement is made by first aligning magnetic nuclei along a magnetic field $M_{0}$ generated by a strong magnet, resulting in a nuclear magnetization $M$ proportional to the number of nuclei in the affected volume of a sample. Because of this realignment of magnetization, a new free-inductiondecay signal, called the spin echo, will occur at time $t$ (Hearst, and others, 2000).

For most liquids, the transverse magnetization decay is exponential, so the amplitude (M) of $\mathrm{n} t h$ spin echo at time $t=$ $n T_{\mathrm{e}}$, where $T_{\mathrm{e}}$ is the echo spacing, is:

$$
M(t)=M \exp \left(-\frac{t}{T_{2}}=M_{0} \exp \left[-\left\{\left(\rho_{2}\left(\frac{A}{V}\right)_{\text {pore }}+\frac{1}{T_{2 B}}\right\} t\right]\right.\right.
$$

where,

$T_{2 \mathrm{~B}}$ is the relaxation time of water in bulk, $\rho_{2}$ is the constant of proportionality between the pore-surface-to-volume ratio $(A / V)$ pore and the NMR relaxation time, and $T_{2}$ is the bulk transverse relaxation time (Kleinberg, Flaum, Straley, and others, 2003).

The spin echo signal from water in large pores decays more slowly than the signal from water in small pores because the relaxation time $T_{2}$ of water in a pore is inversely proportional to the surface-to-volume ratio of the pore, $(A / V)_{\text {pore }}$. Therefore, NMR $T_{2}$ distributions provide for fluid discrimination in sediments (clay-bound water, capillary-bound water, and free water). Because fluids confined to small pores near surface have short $T_{2}$ relaxation times and free fluids in large pores have large $T_{2}$ relaxation times, partitioning the $T_{2}$ distributions allows discrimination between the different fluid components. Adding the amplitudes of the observed fluid $T_{2}$ components together gives a total NMR porosity that generally agrees with the density porosity in water-filled formations. The NMR porosity is lower in gas zones because NMR porosity depends on the total hydrogen content, as is true for neutron porosity.

Hydraulic permeability $(k)$ is proportional to the square of a representative NMR relaxation time. Broadly accepted in oil-field NMR logging is the Kenyon relation (Kenyon, 1992), which is given by:

where,

$$
k=C \phi^{4} T_{2 L M}^{2}
$$

$k$ is the permeability, $T^{2}{ }_{2 \mathrm{LM}}$ is the logarithmic mean value of the $T_{2}$ distribution, and $C$ is a constant dependent on mineralogy.

\section{Log Analysis}

In this study, density, $\mathrm{P}$ - and $\mathrm{S}$-wave velocities, gamma, electrical resistivity, NMR porosity, and NMR permeability $\operatorname{logs}$ were analyzed. Density porosity $(\phi)$ is defined as the space occupied by water and (or) gas hydrate. Porosity implies density porosity in this report. Because the density of gas hydrate is similar to the density of water, it is difficult to separate the effect of gas hydrate from the effect of water in calculating porosity without knowing the amount of gas hydrate in the pore space. Therefore, the density porosity is iteratively corrected after the gas hydrate amount is estimated, 
as shown in Lee and Collett (1999), using a three-component system (matrix, water, and gas hydrate).

As indicated in the previous section, the NMR porosity $\log$ measures the space occupied only by water including claybound water, capillary-bound water, and free water (Singer and others, 1997). Therefore, if the density and the NMR logs record porosity accurately, the concentration of gas hydrate $\left(C_{\mathrm{h}}\right)$ can be calculated from:

where,

$$
C_{h}=\left(1-\phi_{n m r} / \phi\right)
$$

$\phi_{n m r}$ is porosity from the NMR $\log$.

Because $C_{\mathrm{h}}$ is always greater than or equal to zero, the NMR, in theory, is never greater than the density porosity.

Lee and Collett (2001) defined water-filled porosity $\left(\phi_{w}\right)$ as:

$$
\phi_{w}=\left(1-C_{h}\right) \phi
$$

If there are no errors in the NMR and density porosities and in the estimated gas hydrate concentrations, the calculated water-filled porosity is equal to the NMR porosity.

\section{Nuclear Magnetic Resonance, Density, and Core Porosities}

Figure 1 illustrates various types of porosities that were studied. The density porosity shown as a dotted red line is the measured density porosity, which is corrected for the gas hydrate concentration estimated from the electrical resistivity log. The Humble equation (Winsauer and others, 1952) is used to estimate the gas hydrate concentration from the resistivity $\log$ with the resistivity of connate water $R_{\mathrm{w}}=1.246$ $8.47 d / 10,000$, where $d$ is depth in meters.

The NMR porosity is the sum of the volumes of free water and bound water in figure 1 . Note that in a clean sandstone interval (depth 975-995 m), the NMR porosity is much lower than the density porosity, implying that the gas hydrate accumulates in the free water part of the pore space. The gas hydrate concentrations are given by the differences between the NMR and density porosities. Gas hydrate concentrations from the NMR porosity, calculated using equation 3, are shown as a solid blue line in figure 1 . In the depth interval between $995 \mathrm{~m}$ and 1,025 m, the difference between the NMR porosity and density porosity is small, indicating negligible gas hydrate concentrations.

Measured core porosities, shown as dots in figure 1, are similar to the corrected density porosities in the clean sandstone intervals. However, core porosities in the shaly intervals are slightly higher than density porosities.

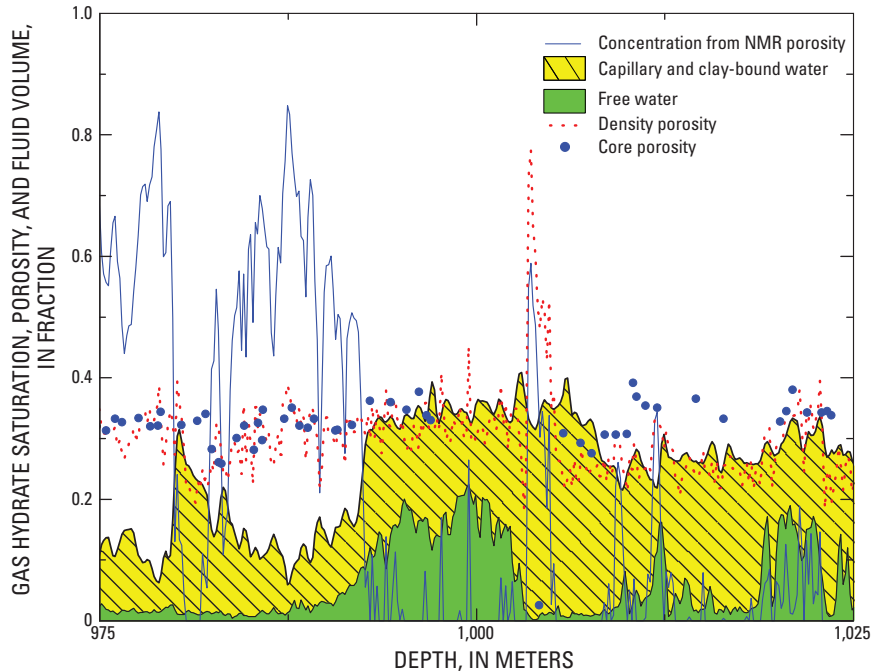

Figure 1. Comparison of various measured porosities and fluid volumes. The gas hydrate concentrations and fluid volumes are calculated from the nuclear magnetic resonance (NMR) log (Schlumberger CMR tool). The sum of volumes of free and bound water is the NMR porosity.

\section{Nuclear Magnetic Resonance and Water-Filled Porosities}

In an ideal case, NMR porosity is identical to the water-filled porosity, as calculated from the density porosity corrected for gas hydrate concentrations. Figure 2 shows a comparison between NMR porosity, density porosity, and water-filled porosity. In figure $2 A$, the NMR porosity is plotted against the density porosity for three different groups of sediments with varying clay content. In the shaded region, shown as hydrated sediments, the difference between NMR and density porosities is large because of the high concentrations of gas hydrate in sediments. Most of the shaly sandstones (clay volume greater than 30 percent) and some of the clean sandstones lie on the 45-degree line, implying negligible gas hydrate concentrations. It is clear that gas hydrate prefers to accumulate in the cleaner sandstone intervals.

Figure $2 B$ shows the water-filled porosity plotted against NMR porosity. As mentioned previously, NMR porosity is the same as water-filled porosity in error-free measurements. The water-filled porosity is calculated from equation 4 using the gas hydrate concentrations estimated from the electrical resistivity log with identical parameters mentioned previously and a saturation exponent of 1.9386. The majority of blue dots and circles (clay content less than 15 percent) follow the 45 -degree 

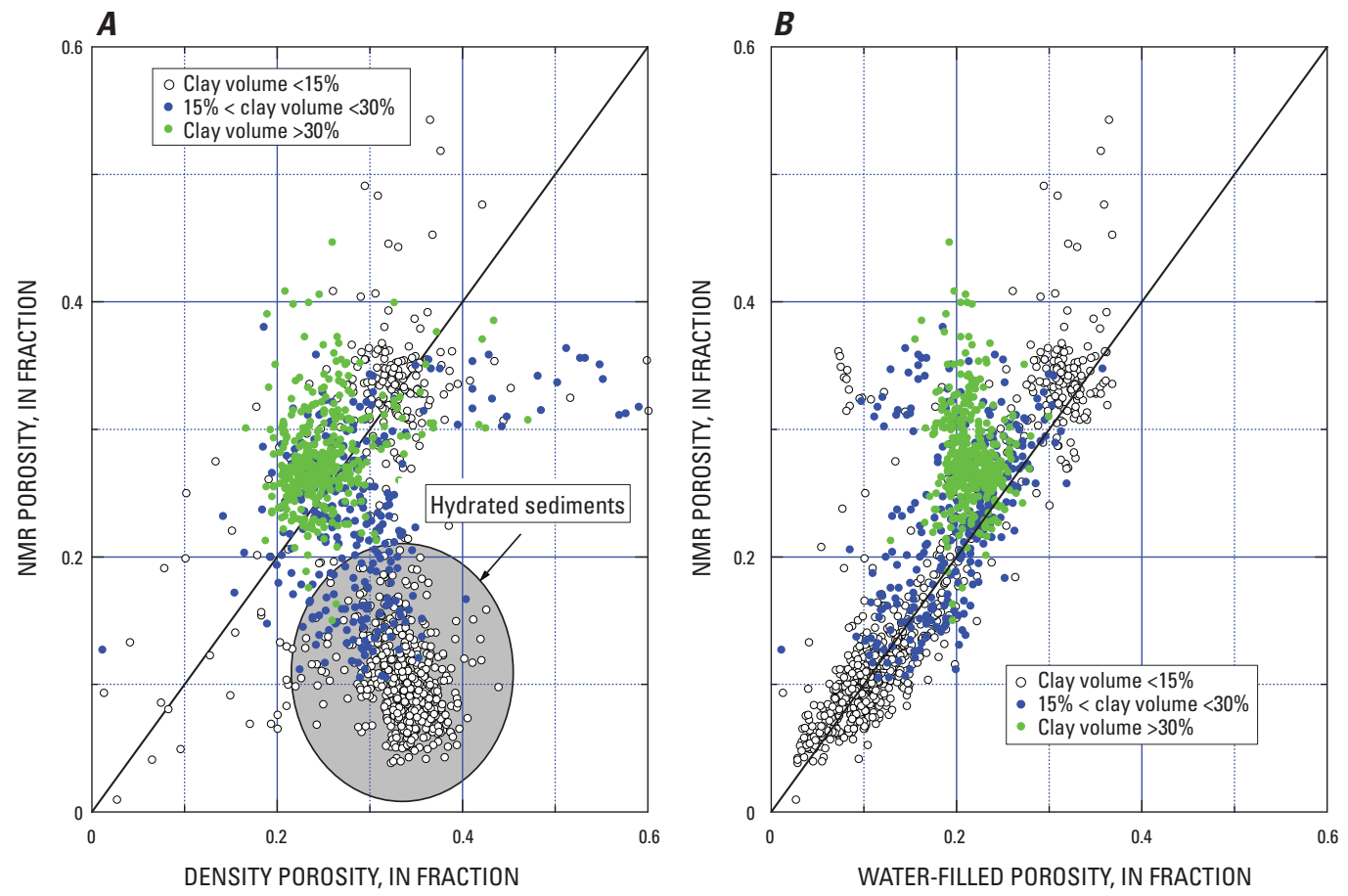

Figure 2. Comparison among density, water-filled, and nuclear magnetic resonance (NMR) porosities within the gas hydrate interval $(891-1,109 \mathrm{~m})$. $\boldsymbol{A}$, Comparison between density and NMR porosities; low NMR porosities compared to the density porosities (within the shaded region) are caused by the presence of gas hydrate. $\boldsymbol{B}$, Comparison between the water-filled porosity calculated from the electrical resistivity log with the Humble equation and the NMR porosity. The discrepancy between two porosities for shaly sandstones $\left(C_{v}>30\right.$ percent $)$ is clearly shown.

line, indicating accurate estimation of gas hydrate concentrations from the resistivity and NMR porosity logs. However, most of the green dots, representing clay content greater than 30 percent, lie above the 45 -degree line, indicating that waterfilled porosity is smaller than NMR porosity. This implies that, in the shaly interval, the electrical resistivity log indicates moderate gas hydrate concentrations, but the NMR log detects negligible gas hydrate. If the clay correction had been applied to the electrical resistivity, the mismatch between the NMR and the water-filled porosity would have been greater because clay is more conductive than sandstone.

At present, it is not known which estimate is more accurate. Therefore, in the following analysis, the data are limited to sediments with clay volume contents less than 12 percent. In this range of clay volume content, the NMR porosity is comparable to the water-filled porosity, and both the NMR and density porosities appear to be "accurate."

\section{Hydraulic Permeability}

Permeability is calculated from equation 2 using the NMR measurement. Because the permeability is highly variable with respect to clay volume content and there exists a discrepancy between the NMR and the water-filled porosity for shaly sandstones, the current analysis of permeability is limited to those samples with $C_{\mathrm{v}}<12$ percent. Figure 3 shows the measured permeability with respect to the NMR porosity and the flow zone indicator (FZI).

FZI is defined by Amaefule and others (1993) as:

$$
F Z I=\frac{0.0314(1-\phi)}{\phi} \sqrt{\frac{k}{\phi}}
$$

where,

$k$ is the permeability in millidarcies $(\mathrm{mD})$.

Rocks with FZI values within a narrow range belong to one hydraulic unit, implying similar flow properties. In each FZI, the porosity-permeability relation can be defined uniquely (Amaefule and others, 1993).

For porosities greater than 20 percent, the permeability of sediments with negligible gas hydrate concentrations lies between $\log (F L Z)=0.0$ and $\log ($ FLZ $)=-0.5$. For high gas hydrate concentrations, the permeability varies between $\log$ $($ FLZ $)=0.0$ and $\log ($ FLZ $)=-1.0$, implying that gas hydrates in sediments alter the flow characteristics of sediments. In other words, the behavior of permeability for non-gas hydratebearing sediments (NGHBS) may not be applicable to the permeability of the GHBS. 


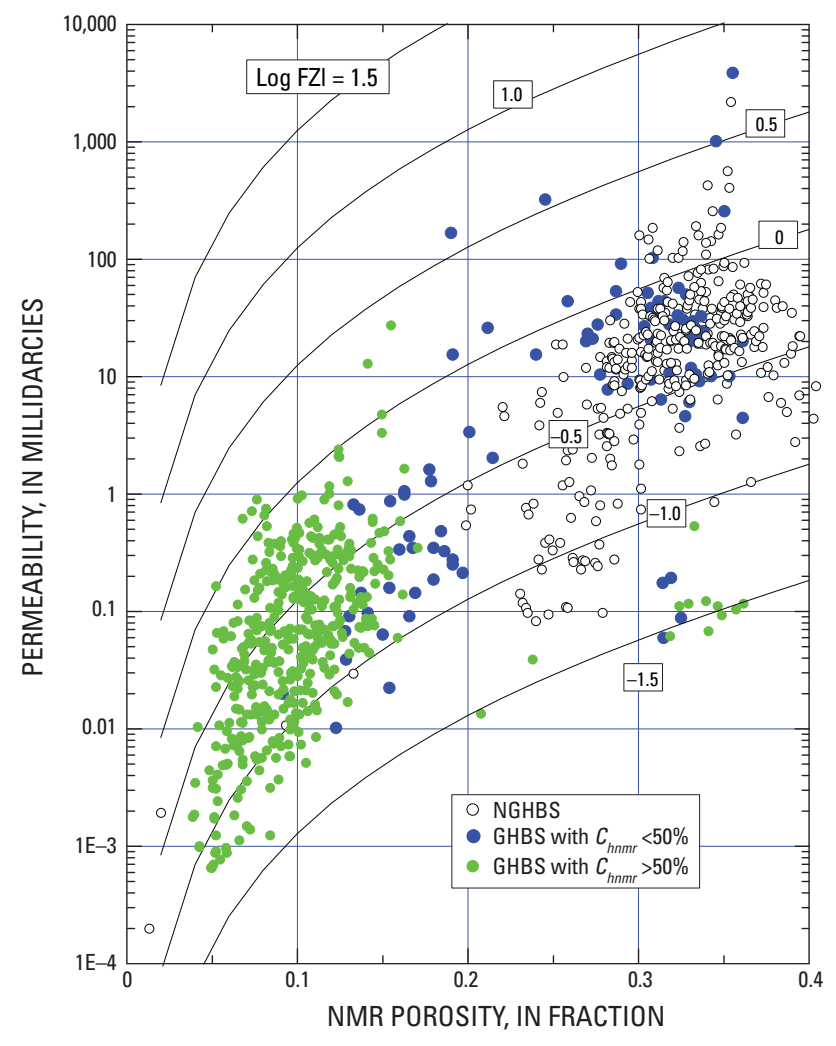

Figure 3. Hydraulic permeability measured from the nuclear magnetic resonance (NMR) log at the Mallik 5L-38 well is plotted with respect to NMR porosity and flow zone indicator (FZI). Measurements are restricted to sediments with $C_{v}<12$ percent within the gas hydrate interval (depth $891-1,109 \mathrm{~m}) . C_{\mathrm{hnmr}}$ is the gas hydrate concentrations estimated from the NMR porosity log. NGHBS, non-gas hydrate-bearing sediment; GHBS, gas hydrate-bearing sediment.

\section{S-Wave Velocity}

S-wave velocities are measured in two orthogonal directions. An S-wave velocity log indicates anisotropy of the sediments, possibly due to the near-vertical fractures at the Mallik 5L-38 well site, and the azimuth of the fast S-wave velocity is about $\mathrm{N} \cdot 40^{\circ} \mathrm{E}$., which coincides with the regional maximum horizontal compressional stress direction (McLellan and others, 2005). Because the true orientation of vertical fractures is not known and the effect of anisotropy is not incorporated into the analysis, a degree of uncertainty remains in the elastic velocity analysis. However, the anisotropy $\log$ indicates that the gas hydrate-bearing sandstone section behaves in an isotropic manner (Plona and Kane, 2005), and the current log analysis is focused on the velocities of clean GHBS. Therefore, the uncertainty associated with anisotropy is deemed to be insignificant.

\section{Theoretical Models}

\section{Permeability Model}

Generally, the permeability of sediments is proportional to porosity and inversely proportional to the tortuosity and specific surface area per unit grain. Therefore, where and how gas hydrate accumulates in the pore spaces has a dramatic effect on the permeability of GHBS. Kleinberg, Flaum, Griffin, and others (2003) studied different permeability models, which are summarized in appendix A.

In order to apply permeability models to measured permeability, the relative permeability should be known. In this study, the permeability of clean sandstone without any gas hydrate concentration is used as the reference permeability, which corresponds to $k_{0}$ in appendix A. As shown in figure 3, the permeability of sandstone near porosity of 35 percent is $50 \mathrm{mD}$. Therefore, the relative permeability is derived by dividing the permeability shown in figure 3 by $50 \mathrm{mD}$, and a subset of measured permeability is shown in figure 4 as dots with respect to the gas hydrate concentrations estimated from the NMR porosity. Measurements shown in figure 4 are for GHBS with $C_{\mathrm{v}}<12$ percent and 34 percent $<\phi<35$ percent. The measured permeability lies between the predicted permeability from the grain-coating model (equation A-4) and that from the LBNL model. Overall, however, the result from the pore-filling model shows the best correlation between predicted and measured values. Also shown as stars are the estimated permeability values from the NMR data interpretation with the Kenyon relation, equation 2, for the Berea Sandstone by Kleinberg, Flaum, Griffin, and others (2003). The trend of relative permeability of Berea Sandstone is similar to the trend of GHBS at the Mallik 5L-38 well.

\section{Elastic Model}

The majority of gas hydrate-bearing sediments occur within unconsolidated sediments because gas hydrate accumulates in the shallow subsurface as determined by the gas hydrate phase stability. The elastic velocities of gas hydrate are higher than those of fluid in sediments, thus gas hydrate increases the elastic velocities of sediments. However, the degree of velocity increase with respect to the amount of gas hydrate depends on how the gas hydrate occurs in the pore space. For the cementation model, in which gas hydrate cements the grain contacts or cements uniformly around the grain, only a small amount of gas hydrate increases the elastic velocity significantly, and the elastic properties of gas hydrate-bearing sediments approaches those of consolidated sediments. For the pore-filling model, the assumption is that gas hydrate does not cement grains, but rather fills the pore space; therefore, the increase of velocity with respect to the gas hydrates is gradual and the elastic properties of GHBS remain as those of unconsolidated sediments. 


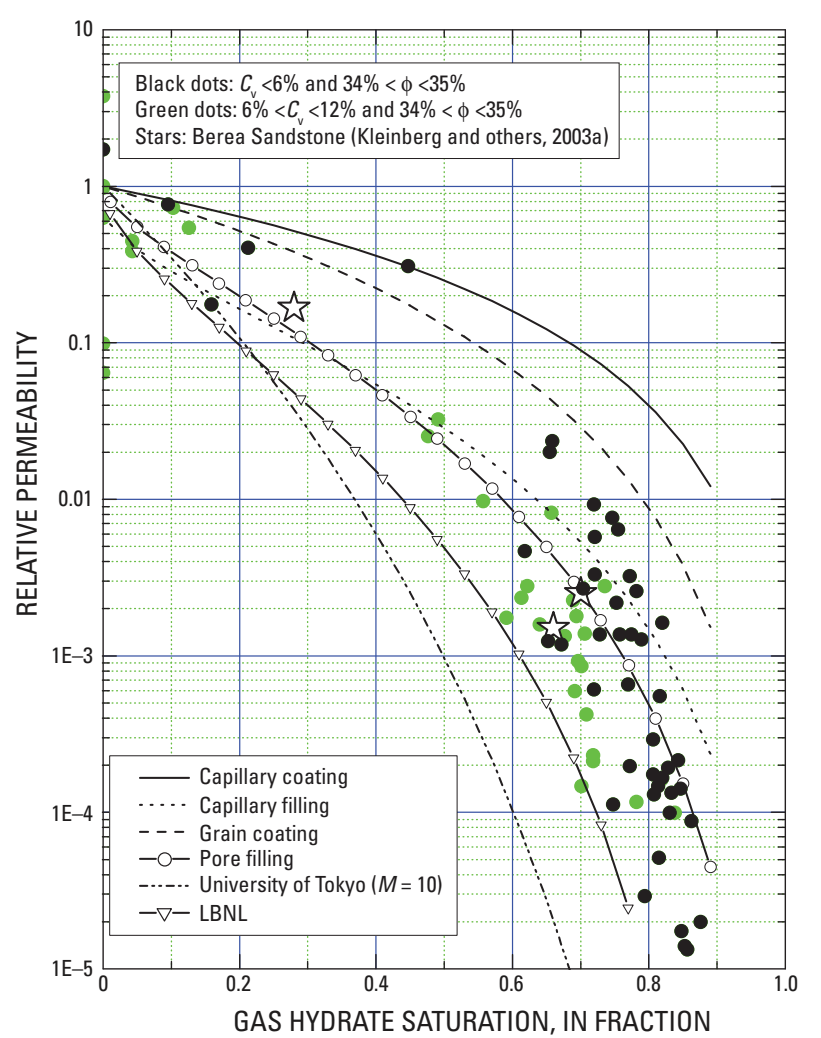

Figure 4. Relative permeability calculated from various permeability models and measured relative permeability at the Mallik $5 \mathrm{~L}-38$ well. The relative permeability is calculated under the assumption that the permeability of non-gas hydrate-bearing sediments is $50 \mathrm{mD}$. The measurements are restricted to samples with $C_{v}<12$ percent and 34 percent $<\phi$ $<35$ percent. LBNL, Lawrence-Berkeley National Laboratory.

A brief description of the cementation theory for GHBS that was developed by Dvorkin and Nur $(1993,1996)$ is given in appendix B. In the present study, cementation theory is applied to a subset of measured velocities (porosity between 34 percent and 35 percent and $C_{\mathrm{v}}<12$ percent) under the assumption that the gas hydrates uniformly coat grains. One key parameter of the cementation theory is the ratio of grain radius to the thickness of the gas hydrate coating the grain $(\delta)$. For a uniform coating, the ratio is given by (appendix B-4):

$$
\delta=\left[\frac{2 C_{h} \phi}{3(1-\phi)}\right]^{0.5}
$$

where,

$\phi$ is the initial porosity without gas hydrate concentration or the density porosity.

Figure 5 shows measured and modeled velocities and velocity ratios using elastic constants shown in table 1 . In the cementation model, $C_{\mathrm{v}}=10$ percent, $\phi=34.5$ percent, and an average number of contacts per grain $\left(n_{\mathrm{c}}\right)$ of 9 are used. Note that at small gas hydrate concentrations, both P- and S-wave velocities predicted by the cementation theory are much higher than measured velocities at the Mallik 5L-38 well.

Elastic velocities of a pore-filling model are calculated using STPBE; a brief description is given in appendix C. The consolidation parameter $\alpha=30$ and elastic constants shown in table 1 are used to calculate velocities, and the results are shown in figure 5 as solid lines. Overall, the measured velocities with respect to gas hydrate concentrations are closer to the results predicted by the pore-filling model.

\section{Discussion}

\section{Permeability of Non-Gas Hydrate-Bearing Sediments}

In deriving the relative permeability of GHBS, it is assumed that the permeability of NGHBS (the reference permeability) with a porosity 34.5 percent is $50 \mathrm{mD}$. The reference permeability used here is orders of magnitude less than some published permeability values. Although the permeability trends with respect to the NMR porosity shown in figure 3 are reasonable, the absolute hydraulic permeability derived from the NMR log may be in error. Figure 6 shows some published permeability values along with those used in this analysis. The rocks measured by Doyen (1988) are consolidated clean sandstones and the least-squares fitting curve with respect to porosity is given by $k=10^{5.65} \phi^{3.81}$ with the correlation coefficient $r=0.98$. The predicted permeability using this empirical relation is about $8,000 \mathrm{mD}$ for a sandstone with a porosity of 34.5 percent. Also plotted in figure 6 are measurements for a variety of clay-bearing sandstones published by Sen and others (1990), for which the empirical relation is given by $k=10^{6.51} \phi^{7.03}$ with $r=0.74$. The predicted permeability using this empirical relation is about $2,000 \mathrm{mD}$ for a sandstone with a porosity of 34.5 percent. Both predicted values are orders of magnitude higher than the reference permeability used in this analysis.

Sediments in this study area are unconsolidated, whereas the rocks used by Doyen (1988) and Sen and others (1990) are consolidated. Permeability of unconsolidated sediments is generally higher than consolidated sediments because of compaction and cementation by decreasing porosity and pore-throat radii. Therefore, the degree of consolidation of sediments at the Mallik 5L-38 well cannot explain the low reference permeability values.

Clay significantly affects the permeability of sediments, causing a decrease of as much or more than two orders of magnitude (Schön, 1996), depending on the clay type. The average clay content of sediments shown in figure 6 for the Mallik 5L-38 well is about 10 percent, and the dominant clay is illite. Therefore, the much lower reference permeability of 


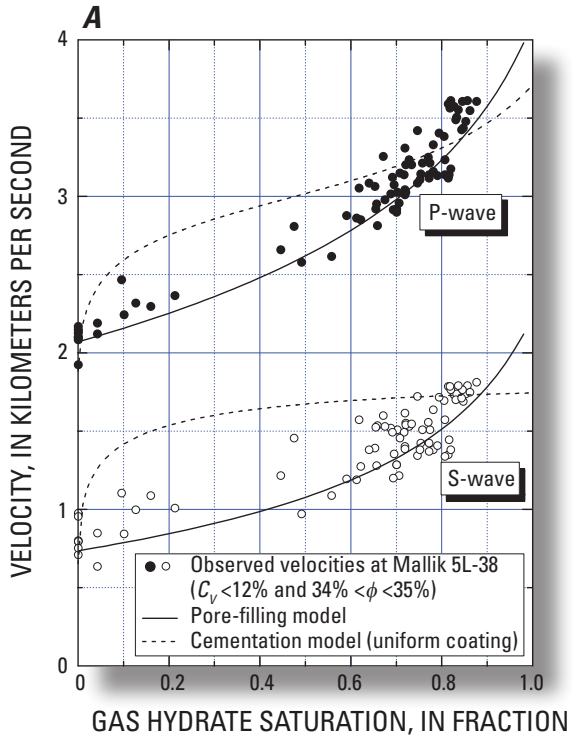

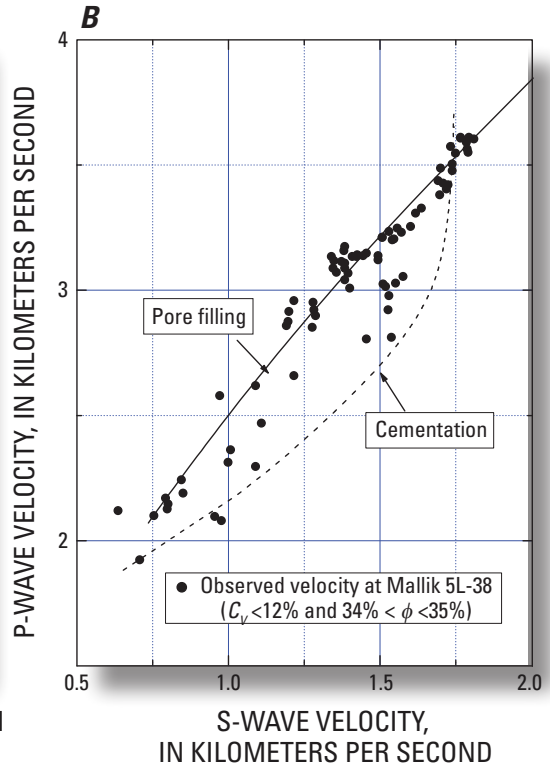

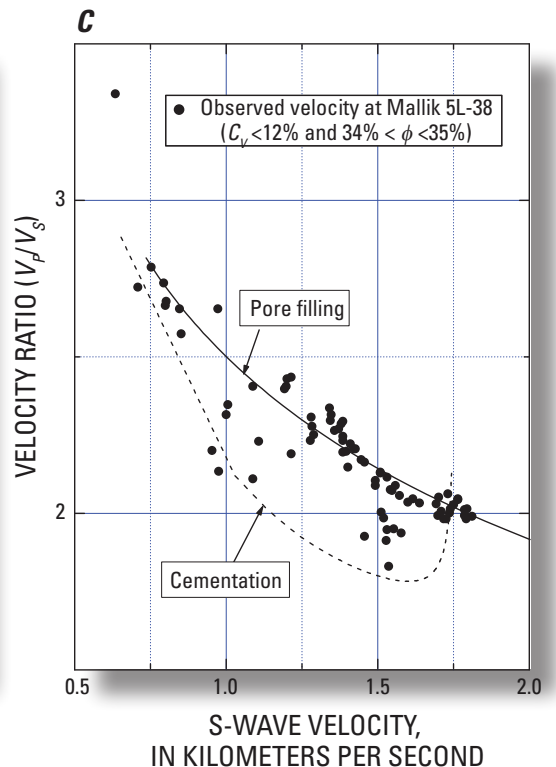

Figure 5. Results of elastic velocities predicted from the cementation and pore-filling models with measured velocities. The measurements are restricted to sediments with $C_{v}<20$ percent and 34 percent $<\phi<35$ percent. $\boldsymbol{A}$, Velocities versus gas hydrate concentrations estimated from the nuclear magnetic resonance (NMR) log. $\boldsymbol{B}, \mathrm{P}$-wave velocity versus $\mathrm{S}$-wave velocity. $\boldsymbol{C}$, Velocity ratio $\left(V_{\mathrm{p}} / V_{\mathrm{s}}\right)$ versus S-wave velocity.

Table 1. Elastic parameters used for computing elastic velocities.

[GPa, gigapascals; $\mathrm{g} / \mathrm{cm}^{3}$, grams per cubic centimeter; *, computed from the Pand S-wave velocities with density given in Sloan (1998)]

\begin{tabular}{lcc}
\hline & Values & Sources \\
\hline $\begin{array}{l}\text { Shear modulus of quartz } \\
\text { Bulk modulus of quartz }\end{array}$ & $\begin{array}{l}44 \mathrm{GPa} \\
38 \mathrm{GPa}\end{array}$ & $\begin{array}{c}\text { Carmichael (1989) } \\
\text { Carmichael (1989) }\end{array}$ \\
$\begin{array}{l}\text { Shear modulus of clay } \\
\text { Bulk modulus of clay }\end{array}$ & $20.85 \mathrm{GPa}$ & Helgerud and others (1999) \\
$\begin{array}{l}\text { Shear modulus } \\
\text { of hydrate }\end{array}$ & $2.54 \mathrm{GPa}$ & Helgerud and others (1999) \\
$\begin{array}{l}\text { Bulk modulus of } \\
\text { hydrate* }\end{array}$ & $6.41 \mathrm{GPa}$ & Sloan (1998) \\
$\begin{array}{l}\text { Density of quartz } \\
\begin{array}{l}\text { Density of clay } \\
\text { Density of hydrate }\end{array}\end{array}$ & $2.65 \mathrm{~g} / \mathrm{cm}^{3}$ & Helgerud and others (1999) \\
\hline
\end{tabular}




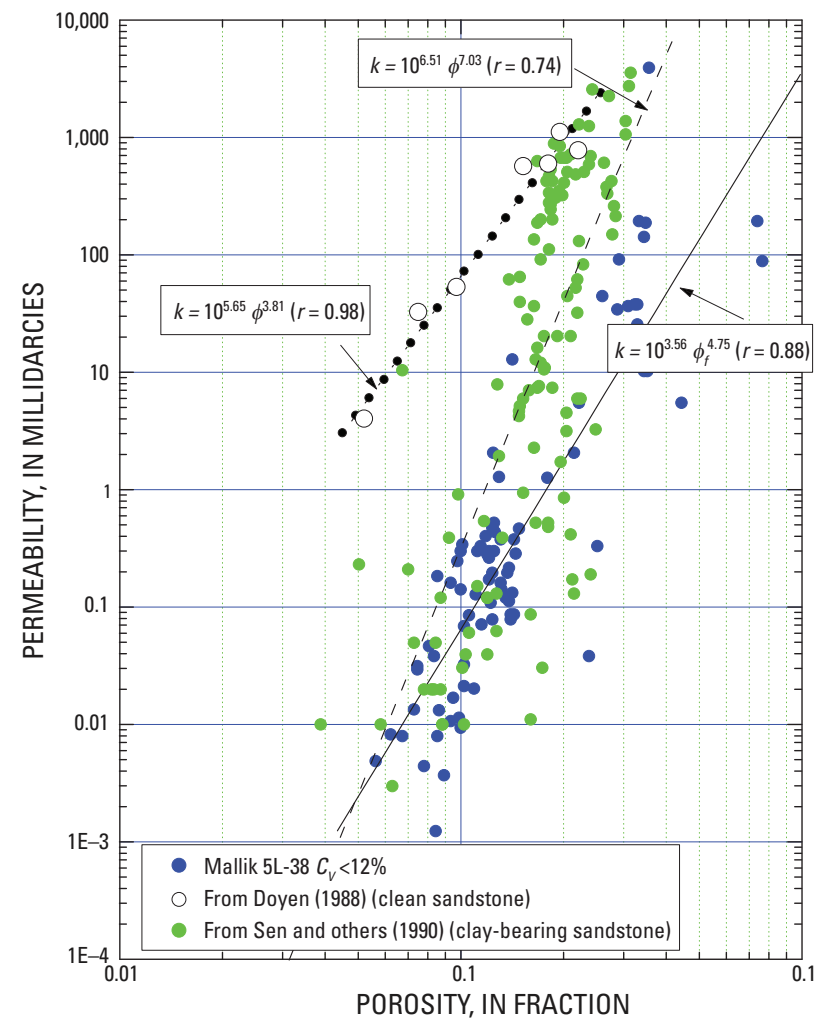

Figure 6. Measured permeabilities with least-squares fitting curves; data from Doyen (1988), Sen and others (1990), and this study $\left(C_{v}<12\right.$ percent and 34 percent $<\phi$ $<35$ percent). $k$, permeability; r, correlation coefficient; porosity.

$50 \mathrm{mD}$ may be partly caused by the presence of illite in sediments.

An interesting point with respect to figure 6 is the exponent of the empirical formula. The exponent for the GHBS (the relation is given by $k=10^{3.56} \phi_{f}^{4.75}$ with $r=0.88$ ) is closer to that of the clean sandstone, whereas the permeability of NGHBS is closer to those of Sen and others (1990) for clay-bearing sandstones. The reduction of porosity and permeability of GHBS at the Mallik 5L-38 therefore appears to result from gas hydrate accumulation in the pore space. If it is assumed that the reduction of porosity and permeability of clay-bearing sandstone measured by Sen and others (1990) result from clay deposition in the pore space, such as the model by Marion and others (1992), the effect of gas hydrate on the permeability of the sediments may differ from that of clay, and it can be concluded that clay has the more pronounced effect on the permeability of the sediment.

All of the exponents deviate from Kozeny-Carman predictions, which is 3.0. According to Doyen (1988), an exponent of 3 is expected to be valid only when pore structure remains microscopically homogeneous as the porosity is reduced. Compaction and cementation of the grains during diagenesis produce an inhomogeneous pore system and requires powers larger than 3 . This implies that gas hydrate in the sediments alters the pore system in sediments, but not as much as clay does. This could be explained by the fact that gas hydrate prefers to form in larger pores.

\section{Pore-Filling and Cementation Models}

Previous analyses of relative permeability and elastic velocities indicate that a pore-filling model is preferable to a cementation or coating model. The rate of permeability decrease with respect to gas hydrate concentrations for the measured permeability is much higher than the predicted rate by capillary or the grain-coating model and much smaller than the University of Tokyo model with $M=10$.

Figures 1 and 4 show that the decrease of permeability with increasing gas hydrate concentration results from gas hydrate forming in the free water portion of the pore space. Gas hydrate growth is inhibited in very small pore spaces, where capillary and clay-bound water is present (Clennell and others, 1999; Henry and others, 1999). Therefore, the maximum amount of gas hydrate in the pore space appears to be limited by the amount of free water, as shown in figure 1 .

The relation between gas hydrate concentration and velocities, shown in figure $5 \mathrm{~A}$, indicates that the pore-filling model is preferable to the cementation model. Comparison between the two models using only measured, not interpreted, values are shown in figures $5 B$ and $5 C$. Figure $5 B$ indicates that for a given $\mathrm{S}$-wave velocity, the cementation model predicts lower P-wave velocities than that of either the measured P-wave velocities or those predicted by the pore-filling model. This implies that in the cementation model, gas hydrate has a more pronounced effect on the shear modulus than on the bulk modulus of the sediment.

It is known that $V_{\mathrm{p}} / V_{\mathrm{s}}$ ratios less than 2.0 are characteristic of well-consolidated water-saturated sediments (Gardner and Harris, 1968). Figure $5 C$ indicates that under the assumption of the cementation model, $V_{\mathrm{p}} / V_{\mathrm{s}}$ ratios are less than 2 when $\mathrm{S}$-wave velocities are greater than about $1.3 \mathrm{~km} / \mathrm{s}$, which corresponds to a gas hydrate concentration of about 5 percent. The $V_{\mathrm{p}} / V_{\mathrm{s}}$ ratio decreases rapidly for small amounts of gas hydrate and increases for higher gas hydrate concentrations. This is caused by the fact that the S-wave velocity is nearly constant for gas hydrate concentrations greater than about 60 percent, whereas the P-wave velocity increases continuously. However, the predicted $V_{\mathrm{p}} / V_{\mathrm{s}}$ ratios by the pore-filling model are greater than 2.0 for all ranges of gas hydrate concentrations and decrease monotonically as gas hydrate concentrations increase.

\section{Combination of Permeability and Elastic Velocities}

The previous discussion focuses on the predictions of various models for either elastic velocities or relative permeabilities. Because a common variable of elastic and 
permeability models is the gas hydrate concentration, it is possible to combine velocity and permeability models, both of which prefer the pore-filling model. In figure 7, the open circles show the relation between the P-wave velocity and the relative permeability for GHBS with $C_{\mathrm{v}}<12$ percent and 20 percent $<\phi<50$ percent, and the blue solid dots for GHBS with $C_{\mathrm{v}}<12$ percent and 34 percent $<\phi<35$ percent. The average clay content of the samples in figure 7 is the same as the one used for the elastic models (that is, $C_{\mathrm{v}}=10$ percent), and the average porosity is 33.5 percent, which is about 1 percent less than the one used for models shown in figures 4 and 5. In figure 7, cementation models are shown as dashed lines and pore-filling models are shown as solid lines. It is clear that where P-wave velocities are greater than about $2.5 \mathrm{~km} / \mathrm{s}$, or where $\mathrm{S}$-wave velocities are greater than $1.0 \mathrm{~km} / \mathrm{s}$, the relation between velocity and relative permeability follows the prediction of the pore-filling model. In this velocity range, the cementation model predicts much higher relative permeability for given velocities. However, for lower velocities, or lower gas hydrate concentrations, the relation is not as clear.

Because the permeability of sediments depends highly on porosity and the clay content, the relative permeabilities derived by dividing the measured permeability by $50 \mathrm{mD}$ may not be accurate for all data used in figure 7. Part of the scattering shown in figure 7 is due to the variable porosity and clay content in sediments.

\section{Conclusions}

Gas hydrate in pore spaces increases elastic velocities and decreases hydraulic permeability. The amount of velocity increase or permeability decrease depends on how the gas hydrate accumulates in the pore space. The NMR porosity log combined with resistivity, velocity, density, and gamma logs provides a means of testing various models for gas hydrate accumulations. From this investigation, the following conclusions can be drawn.

1. The NMR porosity appears to be reliable for clean sandstones, and accurate in-situ gas hydrate concentrations can be estimated using density and NMR porosities.

2. Gas hydrate concentrations estimated from the electrical resistivity log are comparable to those estimated from the NMR porosity log for clean sandstones, but are higher for the shaly sandstones.

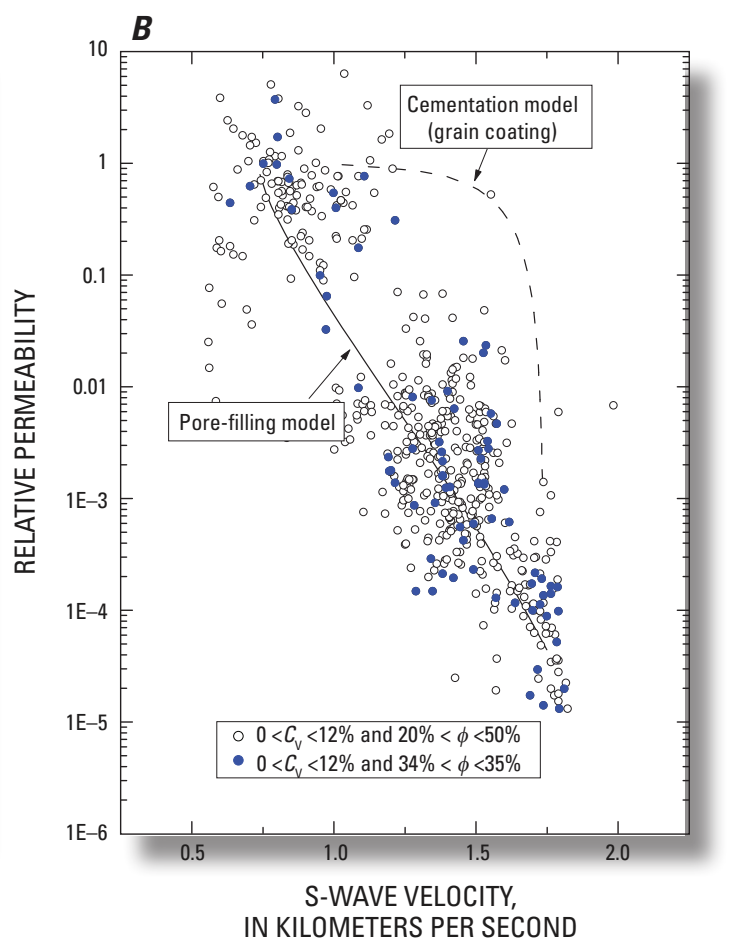

Figure 7. Calculated relative permeability and elastic velocities using the grain-coating (cementation) model and pore-filling model with measured permeabilities and velocities. The measurements are restricted to sediments with $C_{v}<12$ percent and 20 percent $<\phi<50$ percent. $\boldsymbol{A}$, Relative permeability versus $\mathrm{P}$-wave velocity. $\boldsymbol{B}$, Relative permeability versus $\mathrm{S}$-wave velocity. 
3. Relative permeability predicted using a pore-filling model of gas hydrate agrees well with the measured relative permeability for clean sandstone.

4. Elastic velocities of gas hydrate-bearing sediments can be accurately predicted using the three-phase Biot-type equation under the assumptions used in the pore-filling model.

5. The relation between elastic velocities and relative permeabilities predicted from the pore-filling model agrees reasonably well with the measured relation for clean GHBS containing moderate-to-high gas hydrate concentrations. However, at low gas hydrate concentrations, the relation is less clear.

\section{References Cited}

Akihisa, K., Tezuka, K., Senoh, O., and Uchida, T., 2002, Well log evaluation of gas hydrate saturation in the MITI NankaiTrough well, offshore southeast Japan: SPWLA 43rd Annual Logging Symposium, Transactions, BB1-BB14.

Amaefule, J.O., Attunbay, M., Tiab, D., Kersey, D.G., and Keelan, D.K., 1993, Enhanced reservoir description: Using core and log data to identify hydraulic (flow) units and predict permeability in uncored intervals/wells: Society of Petroleum Engineers Paper 26436, p. 1-16.

Carmichael, R.S., 1989, Practical handbook of physical properties of rocks and minerals: Boca Raton, Fla., CRC Press, $741 \mathrm{p}$.

Clennell, M.B., Hovland, M., Booth, H.P., and Winters, W.J., 1999, Formation of natural gas hydrates in marine sediments 1. Conceptual model of gas hydrate growth conditioned by host sediments properties: Journal of Geophysical Research, v. 104, p. 22,985-23,003.

Doyen, P.M., 1988, Permeability, conductivity, and pore geometry of sandstone: Journal of Geophysical Research, v. 93, p. 7,729-7,740.

Dvorkin, Jack, and Nur, A., 1993, Rock physics for characterization of gas hydrate, in Howell, D.G., ed., The future of energy gases: U.S. Geological Survey Professional Paper 1570, p. 293-298.

Dvorkin, Jack and Nur, A., 1996, Elasticity of highporosity sandstones: Theory for two North Sea data sets: Geophysics, v. 61, p. 1,363-1,370.

Ecker, Christine, Lumlet, D., Dvorkin, J., and Nur, A., 1998, Sediments within gas hydrates: Internal structure from seismic AVO: Geophysics, v. 63, p. 1,659-1,669.
Gardner, G.H.F., and Harris, M.H., 1968, Velocity and attenuation of elastic waves in sands: 9th Annual SPWLA Log Symposium, Transitions, M1-M19.

Gassmann, F., 1951, Elasticity of porous media: Vierteljahrsschr der Naturforschenden Gesselschaft, v. 96, p. 1-23.

Guerin, Gilles, Goldberg, D., and Melster, A., 1999, Characterization of in situ elastic properties of gas hydrate-bearing sediments on the Blake Ridge: Journal of Geophysical Research, v. 1004, p. 17,781-17,795.

Hearst, J.R., Nelson, P.H., and Paillett, F.L., 2000, Well logging for physical properties: New York, Wiley, 483 p.

Helgerud, M.B., Dvorkin, J., Nur, A., Sakai, A., and Collett, T.S., 1999, Elastic-wave velocity in marine sediments with gas hydrates: Effective medium modeling: Geophysical Research Letters, v. 26, p. 2,021-2,024.

Henry, P., Thomas, M., and Clennell, M.B., 1999, Formation of natural gas hydrates in marine sediments 2: Thermodynamic calculations of stability conditions in porous sediments: Journal of Geophysical Research, v. 104, p. $23,005-23,022$.

Hill, R., 1952, The elastic behavior of crystalline aggregates: London, Proceedings of the Physical Society, v. A65, p. 349-354.

Hyndman, R.D., and Spencer G.D., 1992, A seismic study of methane hydrate marine bottom simulating reflectors: Journal of Geophysical Research, v. 97, p. 6,683-6,698.

Jakobsen, M., Hudson, J.A., Minshull, T.A., and Singh, S.C., 2000, Elastic properties of hydrate-bearing sediments using effective medium theory: Journal of Geophysical Research, v. 105 , p. 561-577.

Kenyon, W.E., 1992, Nuclear magnetic resonance as a petrophysical measurement: Nuclear Geophysics, v. 6, p. 153-171.

Kleinberg, R.L., Flaum, C., Griffin, D.D., Brewer, P.G., Malby, G.E., Peltzer, E.T., and Yesinowski, J.P., 2003, Deep sea NMR: Methane hydrate growth habit in porous media and its relation to hydraulic permeability, deposit accumulation, and submarine slope stability: Journal of Geophysical Research, v. 108, no. B10, 2508, doi:10.1029/2003JB002389.

Kleinberg, R.L., Flaum, C., Straley, C., Brewer, P.G., Malby, G.E., Peltzer, E.T., Friederich, G., and Yesinowski, J.P, 2003, Seafloor nuclear magneto resonance assay of methane hydrate sediment and rock: Journal of Geophysical Research, v. 108, no. B3, 2137, doi:10.1029/2001JB000919. 
Kleinberg, R.L., Flaum, C., and Collett, T.S., 2005, Magnetic resonance log of JAPEX/JNOC/GSC and others Mallik 5L-38 gas hydrate production research well: Gas hydrate saturation, growth habit, relative permeability, in Dallimore, S.R., and Collett, T.S., eds., Scientific results from the Mallik 2002 gas hydrate production research well program, Mackenzie Delta, Northwest Territories, Canada: Geological Survey of Canada, Bulletin 585, 10 p.

Leclaire, P., Cohen-Tenoudji, F., and Aguirre-Puente, J., 1994, Extension of Biot's theory of wave propagation to frozen porous media: Journal of Acoustical Society of America, v. 96 , p. 3,753-3,768.

Lee, M.W., 2002, Biot-Gassmann theory for velocities of gashydrate-bearing sediments: Geophysics, v. 67, p. $1,711-1,719$.

Lee, M.W., 2005, Proposed moduli of dry rock and their application to predicting elastic velocities of sandstones: U. S. Geological Survey Scientific Investigation Report 2005-5119, 14 p.

Lee, M.W., 2007, Velocities and attenuations of gas hydratebearing sediments: U.S. Geological Survey Scientific Investigations Report 2007-5264, 11 p.

Lee, M.W., and Collett, T.S., 1999, Gas hydrate amount estimated from compressional and shear-wave velocities at the JAPEX/JNOC/GSC Mallik 2L-38 gas hydrate research well, in Dallimore, S.R., Uchida, T., and Collett, T.S., eds., Scientific results from JAPEX/JNOC/GSC and shearwave velocities at the JAPEX/JNOC/GSC Mallik 2L-38 gas hydrate research well, Mackenzie Delta, Northwest Territories, Canada: Geological Survey of Canada Bulletin 544, p. 313-322.

Lee, M.W., and Collett, T.S., 2001, Elastic properties of gas hydrate-bearing sediments: Geophysics, v. 66, p. 763-771.

Marion, Dominique, Nur, A., Yin, H., and Han, D., 1992, Compressional velocity and porosity in sand-clay mixture: Geophysics, v. 57, p. 554-563.

Masuda, Y., Naganawa, S., Ando, S., and Sato, K., 1997, Numerical calculations of gas production performance from reservoirs containing natural gas hydrates: Annual Technical Conference, Paper 38291, Society of Petroleum Engineers, San Antonio, Texas, Oct. 1997.

McLellan, P.J., Gillen, K.P., Podetz, C.G., Dallimore, S.R., Inoue, T., and Hancock, S.H., 2005, In situ stresses in the Mallik area, in Dallimore, S.R., and Collett, T.S., eds., Scientific results from the Mallik 2002 gas hydrate production research well program, Mackenzie Delta, Northwest Territories, Canada: Geological Survey of Canada, Bulletin 585, 15 p.
Parker, J.C., Lenhard, R.J., and Kuppusamy, T., 1987, A parametric model for constitutive properties governing multiphase flow in porous media: Water Resources Research, v. 23, p. 618-624.

Plona, T.J., and Kane, M.R., 2005, Anisotropic stress analysis from downhole acoustic logs in the JAPEX/JNOC/GSC et al. Mallik 5L-38 gas hydrate production research well, in Dallimore, S.R., and Collett, T.S., eds., Scientific results from the Mallik 2002 gas hydrate production research well program, Mackenzie Delta, Northwest Territories, Canada: Geological Survey of Canada, Bulletin 585, 8 p.

Pride, S.R., Berryman, J.G., and Harris, J.M., 2004, Seismic attenuation to wave-induced flow: Journal of Geophysical Research, v. 109, B01201, doi:10.1029/2003JB002639.

Schön, J.H.,1996, Physical properties of rocks: Fundamental and principles of petrophysics: Pergamon, $583 \mathrm{p}$.

Sen, P.N., Straley, C., Kenyon, W.E., and Whittingham, M.S., 1990, Surface-to-volume ratio, charge density, nuclear magnetic relaxation, and permeability in clay-bearing sandstones: Geophysics, v. 55, p. 61-69.

Singer, J.M., Johnston, L., Kleinberg, R.L., and Flaum, C., 1997, Fast NMR logging for bound fluid and permeability: SPWLA 38th Annual Logging Symposium, Transactions, YY1-YY13.

Sloan, E.D., Jr., 1998, Clathrate hydrates of natural gases: New York, Mercel Dekker, 705 p.

Winsauer, W.O., Shearin, H.M., Jr., Masson, P.H., and Williams, M., 1952, Resistivity of brine-saturated sands in relation to pore geometry: American Association of Petroleum Geologists Bulletin, v. 36, p. 253-277.

Winters, W.J., Pecher, I.A., Booth, J.S., Mason, D.H., Relle, M.K., and Dillon, W.P., 1999, Physical properties of samples containing natural gas hydrate from the JAPEX/JNOC/ GSC Mallik 2L-38 gas hydrate research well, determined using gas hydrate and sediment test laboratory instrument (GHASTLI), in Dallimore, S.R., Uchida, T., and Collett, T.S., eds., Scientific results from JAPEX/JNOC/GSC Mallik 2L-38 gas hydrate research well, Mackenzie Delta, Northwest Territories, Canada: Geological Survey of Canada Bulletin 544, p. 241-250. 


\section{Models for Gas Hydrate-Bearing Sediments Inferred from Hydraulic Permeability and Elastic Velocities}

\section{Appendix A. Permeability Model}

This appendix summarizes the various permeability models used in estimating gas hydrate concentrations in sediments (Kleinberg, Flaum, Griffin, and others, 2003).

Let $C_{\mathrm{h}}$ be the gas hydrate concentration in sediments having an initial porosity of $\phi$. Relative permeability $\left(k_{\mathrm{rw}}\right)$, defined as the ratio of permeability of the models divided by the permeability of the simplest model (a porous medium that consists of a bundle of straight, parallel cylindrical capillaries having an inner radius of $a$ ), is given by:

$$
k_{o}=\frac{n \pi a^{2}}{8}=\frac{\phi a^{2}}{8}
$$

Therefore, the permeability of a porous medium without gas hydrate is given by $k_{0}$.

1. Hydrate coats capillary walls:

$$
k_{r w}=\frac{k}{k_{o}}=\left(1-C_{h}\right)^{2}
$$

2. Hydrate occupies capillary centers:

$$
k_{r w}=1-C_{h}^{2}+\frac{2\left(1-C_{h}\right)^{2}}{1 n\left(C_{h}\right)}
$$

3. Hydrate coats grains:

$$
k_{r w}=\left(1-C_{h}\right)^{n+1}
$$

where,

$n$ is the Archie saturation exponent.

4. Hydrate occupies pore center or pore filling:

$$
k_{r w}=\frac{\left(1-C_{h}\right)^{n+2}}{\left(1+\sqrt{C_{h}}\right)^{2}}
$$

5. University of Tokyo model (Masuda and others, 1997):

$$
k_{r w}=\left(1-C_{h}\right)^{M}
$$

where,

$$
M=10 \text { or } 15
$$

6. Lawrence Berkeley National Laboratory (LBNL) model:

$$
k_{r w}=\sqrt{S_{w}^{*}}\left[1-\left\{1-\left(S_{w}^{*}\right)^{1 / m}\right\}\right]^{2}
$$

where,

$$
S_{w}^{*}=\frac{S_{w}-S_{r}}{1-S_{r}}
$$

and,

$S_{\mathrm{w}}$ is the water saturation, that is $1-C_{\mathrm{h}}$, and $S_{\mathrm{r}}$ is the irreducible water saturation. Typically in sandstone, $S_{\mathrm{r}}^{\mathrm{r}}=0.09$ and $m=0.46$ (Parker and others, 1987). 


\section{Appendix B. Cementation Theory}

The cementation theory for gas hydrate concentration is given by Dvorkin and Nur $(1993,1996)$. The effective dryrock bulk $\left(k_{\text {eff }}\right)$ and shear $\left(\mu_{\text {eff }}\right)$ moduli are:

where,

$$
\begin{aligned}
& k_{\text {eff }}=\frac{n_{c}(1-\phi)}{6}\left(k_{h}+\frac{4 \mu_{h}}{3}\right) S_{n} \\
& \mu_{e f f}=\frac{3 k_{e f f}}{5}+\frac{3 n(1-\phi) \mu_{h} S_{\tau}}{20}
\end{aligned}
$$

$n_{\mathrm{c}}$ is the average number of contacts per grain, $\phi$ is the initial porosity of sediment without a gas hydrate, and $k_{h}$ and $\mu_{h}$ are bulk and shear moduli of the pure gas hydrate, respectively. Parameters $S_{n}$ and $S_{\tau}$ are given by:

$S_{n}=A_{n}\left(\Lambda_{n}\right) \alpha^{2}+B_{n}\left(\Lambda_{n}\right) \alpha+C_{n}\left(\Lambda_{n}\right)$

$A_{n}\left(\Lambda_{n}\right)=-0.024153 \Lambda_{n}^{-1.3646}$

$B_{n}\left(\Lambda_{n}\right)=0.20405 \Lambda_{n}^{-0.89008}$

$$
C_{n}\left(\Lambda_{n}\right)=0.00024649 \Lambda_{n}^{-1.9846}
$$

$S_{\tau}=A_{\tau}\left(\Lambda_{\tau}, v\right) \alpha^{2}+B_{\tau}\left(\Lambda_{\tau}, v\right) \alpha+C_{\tau}\left(\Lambda_{\tau}, v\right)$

$A_{\tau}\left(\Lambda_{\tau}, v\right)=-10^{-2}\left(2.26 v^{2}+2.07 v+2.3\right) \Lambda_{\tau}^{0.079 v^{2}+0.1754 v-1.342}$

$B_{\tau}\left(\Lambda_{\tau}, v\right)=\left(0.0573 v^{2}+0.0937 v+0.202\right) \Lambda_{\tau}^{0.0274 v^{2}+0.0529 v-0.8765}$

$C_{\tau}\left(\Lambda_{\tau}, v\right)=10^{-4}\left(9.654 v^{2}+4.945 v+3.1\right) \Lambda_{\tau}^{0.01867 v^{2}+0.4011 v-1.8186}$

$\Lambda_{n}=\frac{2 \mu_{h}(1-v)\left(1-v_{h}\right)}{\pi \mu\left(1-2 v_{h}\right)}, \Lambda_{\tau}=\frac{\mu_{h}}{\pi \mu}$

where,

$\mu$ and $v$ are the shear modulus and the Poisson's ratio of the grain, respectively; $\mu_{h}$ and $v_{h}$ are the shear modulus and the Poisson's ratio of the pure gas hydrate respectively; $\delta$ is the ratio of the gas hydrate contact radius to the grain radius. If all hydrate is deposited at the grain contacts, then:

$$
\delta=2\left[\frac{C_{h} \phi}{3 n_{c}(1-\phi)}\right]^{0.25}
$$

But if hydrate evenly coats every grain, then:

$$
\delta=\left[\frac{2 C_{h} \phi}{3(1-\phi)}\right]^{0.5}
$$

Effective bulk and shear moduli of water-saturated sediments are calculated from the above dry rock moduli by the fluid substitution of Gassmann's (1952) formula and moduli of composite matrix (that is, quartz, clay, and gas hydrate) is computed using Hill's (1952) averaging method. 


\section{Appendix C. Three-Phase Biot-Type Equation}

Using the stiffness matrix $\left(R_{i j}\right)$ and the shear matrix $\left(\mu_{\mathrm{ij}}\right)$, the P-wave $\left(V_{\mathrm{p}}\right)$ velocities and the shear-wave velocities $\left(V_{\mathrm{s}}\right)$ of gas hydrate-bearing sediments (GHBS) at low frequency ignoring the attenuation are given by the following equation (Lee, 2007):

$$
V_{p}=\sqrt{\frac{\sum_{i, j=1}^{3} R_{i j}}{\rho_{b}}}=\sqrt{\frac{k+4 \mu / 3}{\rho_{b}}} \text { and } V_{S}=\sqrt{\frac{\sum_{i, j=1}^{3} \mu_{i j}}{\rho_{b}}}=\sqrt{\frac{\mu}{\rho_{b}}} \quad(\mathrm{C}-1)
$$

where,

$k$ and $\mu$ are bulk and shear moduli of the GHBS, $\rho_{\mathrm{b}}$ is the bulk density of GHBS given by $\rho_{\mathrm{b}}=\rho_{\mathrm{s}}(1-\phi)+\rho_{w} \phi\left(1-C_{h}\right)$ $+\rho_{h} \phi C_{h}$, and subscripts $s, w$, and $h$ refer to sediment grain, water, and gas hydrate, respectively.

Assuming that the gas hydrate acts as a load-bearing component of the matrix, the elements of $R_{\mathrm{ij}}$ and $\mu_{\mathrm{ij}}$ are given by:

$$
\begin{gathered}
R_{11}=\left[\left(1-c_{1}\right) \phi_{s}\right]^{2} K_{a v}+K_{s m}+4 \mu_{11} / 3 \\
R_{12}=R_{21}=\left(1-c_{1}\right) \phi_{s} \phi_{w} K_{a v} \\
R_{13}=R_{31}=\left(1-c_{1}\right)\left(1-c_{3}\right) \phi_{s} \phi_{h} K_{a v}+2 \mu_{13} / 3 \\
R_{22}=\phi_{w}^{2} K_{a v} \\
R_{23}=\left(1-c_{3}\right) \phi_{h} \phi_{w} K_{a v} \\
R_{33}=\left[\left(1-c_{3}\right) \phi_{h}\right]^{2} K_{a v}+K_{h m}+4 \mu_{33} / 3 \\
\mu_{11}=\left[\left(1-g_{1}\right) \phi_{s}\right]^{2} \mu_{a v}+\mu_{s m} \\
\mu_{12}=\mu_{21}=\mu_{22}=\mu_{23}=\mu_{32}=0 \\
\mu_{13}=\left(1-g_{1}\right)\left(1-g_{3}\right) \phi_{2} \phi_{h} \mu_{a v} \\
\mu_{33}=\left[\left(1-g_{3}\right) \phi_{h}\right]^{2} \mu_{a v}+\mu_{h m}
\end{gathered}
$$

where,

$$
\begin{gathered}
\phi_{s}=1-\phi, \phi_{w}=\left(1-C_{h}\right) \phi, \phi_{h}=C_{h} \phi, c_{1}=\frac{K_{s m}}{\phi_{s} K_{s}}, c_{3}=\frac{K_{h m}}{\phi_{h} K_{h}}, g_{1}=\frac{\mu_{s m}}{\phi_{s} \mu_{s}}, g_{3}=\frac{\mu_{h m}}{\phi_{h} \mu_{h}}, \\
K_{a v}=\left[\frac{\left(1-c_{1}\right) \phi_{s}}{K_{s}}+\frac{\phi_{w}}{K_{w}}+\frac{\left(1-c_{3}\right) \phi_{h}}{K_{h}}\right]^{-1}, \mu_{a v}=\left[\frac{\left(1-g_{1}\right) \phi_{s}}{\mu_{s}}+\frac{\phi_{w}}{2 \omega \eta}+\frac{\left(1-g_{3}\right) \phi_{h}}{\mu_{h}}\right]^{-1},
\end{gathered}
$$

$\omega$ is an angular frequency and $\eta$ is the pore fluid viscosity. The subscripts $s m$ and $\mathrm{hm}$ refer to the sediment matrix and to the hydrate matrix, respectively.
In the proposed moduli shown in Lee (2007), moduli formed by gas hydrate, that is $K_{h m}$ and $\mu_{h m}$ are negligible compared to the moduli formed by grains, that is $K_{s m}$ and $\mu_{s m}$. Because small magnitudes of $K_{h m}$ and $\mu_{h m}$ only affect the slow wave velocities significantly, these values can be ignored for the computation of the fast velocities, which the logging tools measure. Also the fluid effect on $\mu_{a v}$ is negligible when the frequency is less than logging frequencies (about $30 \mathrm{KHz}$ ). Therefore, three-phase Biot-type (TPBE) applicable to the logging or seismic data can be simplified with $\mathrm{K}_{h m}=0, \mu_{h m}=0$, $\mu_{a v}=0, c_{3}=0$, and $\mathrm{g}_{3}=0$, and the TPBE shown in equations $\mathrm{C}-1$ and $\mathrm{C}-2$ can be simplified as:

$$
\begin{aligned}
& k=K_{s}\left(1-\beta_{p}\right)+\beta_{p}^{2} K_{a v} \\
& \mu=\mu_{s}\left(1-\beta_{s}\right)
\end{aligned}
$$

with,

$$
\begin{aligned}
& \frac{1}{K_{a v}}=\frac{\left(\beta_{p}-\phi\right)}{K_{s}}+\frac{\phi_{w}}{K_{w}}+\frac{\phi_{h}}{K_{h}}, \\
& \beta_{p}=\frac{\phi_{a s}(1+\alpha)}{\left(1+\alpha \phi_{a s}\right)}, \text { and } \beta_{\mathrm{s}}=\frac{\phi_{a s}(1+\gamma \alpha)}{\left(1+\gamma \alpha \phi_{a s}\right)} .
\end{aligned}
$$

where,

$\alpha$ is the consolidation parameter (Pride and others, 2004; Lee, 2005)

with,

$$
\gamma=\frac{1+2 \alpha}{1+\alpha} \text { and } \phi_{\mathrm{as}}=\phi_{w}+\varepsilon \phi_{h} .
$$

Lee (2007) recommended $\varepsilon=0.12$ for modeling velocities of GHBS.

The use of equations $\mathrm{C}-1$ and $\mathrm{C}-3$ is referred to as simplified three-phase Biot-type equation (STPBE) in this report. For water-saturated sediments, STPBE is the same as the BiotGassmann equation. 
Publishing support provided by:

Denver Publishing Service Center

For more information concerning this publication, contact:

Team Chief Scientist, USGS Central Energy Resources

Box 25046, Mail Stop 939

Denver, CO 80225

(303) 236-1647

Or visit the Central Energy Resources Team site at: http://energy.cr.usgs.gov/ 
